\title{
Sistem Pendukung Keputusan Rekrutmen Karyawan Dengan Menggunakan Metode Profile Matching Berbasis Web
}

\author{
Sindhu Rakasiwi ${ }^{1 *}$, Haryo Kusumo ${ }^{2 *}$, Indra Laila ${ }^{3 *}$ \\ ${ }^{1}$ Manajemen Informatika, Universitas Sains dan Teknologi Komputer \\ ${ }^{2}$ Komputerisasi Akuntansi, Universitas Sains dan Teknologi Komputer \\ ${ }^{3}$ Manajemen Informatika, Universitas Sains dan Teknologi Komputer \\ *Corresponding Author.E-mail:sindhu@stekom.ac.id
}

\begin{abstract}
Abstrak
Seleksi karyawan adalah kegiatan memilih, dan menetapkan sejumlah pelamar yang memiliki ilmu dan kemampan yang mumpuni serta mendapatkan karyawan baru yang berkualitas. PT. Trisakti Mustika Graphika adalah perusahaan yang bergerak dibidang percetakan. PT. Trisakti perlu adanya perekrutan agar mendapatkan karyawan baru yang mampu membantu perusahaan agar perusahaan menjadi lebih maju. Dalam sistem perekrutan karyawan baru, PT. Trisakti harus mempertimbangkan kriteria yang ada di perusahaan agar mendapat nilai yang objektif, akurat dan sesuai dengan kemampuan pelamar. Kurangnya efektifitas waktu karena perekrutan dilakukan dengan manual serta sulitnya menghilangkan faktor subyektif dari manager HRD. Adapun pendukung keputusan untuk perekrutan karyawan baru dengan diterapkannya metode profile matching. metode profile matching adalahproses pengambilan keputusan dengan memasukkan nilai-nilai ideal dan mengetahui kemampuan pelamar karena penghitungannya menggunakan system pembobotan. Perancangan ini bertujuan untuk membantu staff dalam merekrut karyawan baru agar waktu yang digunakan untuk penilaian lebih cepat serta mendapatkan karyawan-karyawan yang berkualitas dan sesuai dengan kemampuannya. Dari hasil penelitian ini di dapat, bahwa sistem ini dapat menyeleksi karyawan dengan baik di buktikan dengan hasil validasi mendapat point 3 yang berkategori baik yang berada di range $2,00-3,00$.
\end{abstract}

Kata Kunci : Sistem Pendukung Keputusan, Rekrutmen, Metode Profile Matching

\begin{abstract}
Employee selection is an activity to select, and determine a number of applicants who have good knowledge and skills and get qualified new employees. PT. Trisakti Mustika Graphika is a company engaged in printing. PT. Trisakti needs recruitment in order to get new employees who are able to help the company so that the company becomes more advanced. In the new employee recruitment system, PT. Trisakti must consider the criteria that exist in the company in order to get an objective, accurate and in accordance with the ability of the applicant. Lack of time effectiveness because recruitment is done manually and the difficulty of
\end{abstract}


eliminating subjective factors from HRD managers. The decision support for the recruitment of new employees by applying the profile matching method. The profile matching method is a decision-making process by entering ideal values and knowing the applicant's abilities because the calculation uses a weighting system. This design aims to assist staff in recruiting new employees so that the time used for assessment is faster and to get qualified employees according to their abilities. From the results of this study, it can be seen that this system can select employees well, as evidenced by the validation results getting point 3 which is categorized as good which is in the range of 2.00-3.00.

Keywords: Decision Support System, Recruitment, Profile Matching Method

\section{Introduction}

Organisasi adalah suatu sistem perserikatan formal, berstruktur, dan terkoordinasi dari sekelompok orang yang bekerja sama dalam mencapai tujuan tertentu. Organiasi hanya merupakan alat dan wadah saja (Malayu Hasibuan). Dalam menjalankan bisnis perusahaan,maka dibutuhkan sumber daya manusia atau perencanaan tenaga kerja yang memiliki kemampuan yang memadai. Didalam perusahaan juga perlu perencanaan tenaga kerja, yaitu menyediakan tenaga kerja yang tepat pada jabatan yang tepat pada waktu yang tepat. Dengan adanya itu perusahaan dapat menjaga eksistensinya serta meningkatkan kinerja karyawan.

Didalam perusahaan, kemampuan juga harus menjadi tolak ukur atau pertimbangan agar perusahaan yang dijalankan tetap berjalan sesuai prosedur atau sesuai perencanaan. Mampu adalah cakap menjalankan tugas, mampu, dan cekatan. Kata kemampuan sama artinya dengan kecekatan. Mampu atau kecekatan adalah kepandaian melakukan sesuatu pekerjaan dengan cepat dan benar. Seseorang yang dapat melakukan dengan cepat tetapi salah tidak dapat dikatakan mampu. Sumber daya manusia adalah proses pengelolaan manusia, melalui perencanaan, rekrutmen, seleksi, pelatihan, pemberian kompensasi, karier, keselamatan dan kesehatan serta menjaga hubungan industri sampai pemutusan hubungan kerja guna mencapai tujuan perusahaan dan peningkatan kesejahteraan stakeholder (Kasmir,2016). Dengan adanya sumber daya manusia (SDM) yang mumpuni perusahaan mempunyai modal besar, Proses sumber daya manusia yang tidak sesuai akan memperlambat tujuan perusahaan, dimana manajemen sumber daya manusia menurut Hasibuan (2007:6) adalah ilmu dan seni yang mengatur hubungan dan peranan tenaga kerja agar efektif dan efisien untuk membantu terwujudnya tujuan perusahaan dan masyarakat. Karena seluruh kegiatan 
manajemen yang mengoperasikan adalah manusia.

PT. Trisakti Mustika Graphika adalah perusahaan manufaktur bidang security printing (percetakan dokumen rahasia).Yang dulunya bernama UD. Trisakti pada tahun 1968 dan berganti nama menjadi PT. Trisakti Mustika Graphika pada tahun 1991 sampai sekarang. Agar bisnisnya berjalan sesuai rencana, perusahaan ini melakukan perekrutan karyawan untuk mendapatkan karyawan baru yang sesuai dengan kriteria perusahaan dan jabatan yang dibutuhkan.Menurut Sadili Samsudi (2010) "Rekrutmen adalah proses mendapatkan sejumlah calon tenaga kerja yang kualified untuk jabatan/pekerjaan tertentu dalam suatu organisasi atau perusahaan". Karyawan merupakan orangorang yang melakukan sesuatu untuk perusahaan yang membuat perusahaan tetap berjalan sesuai rencana yang di ganti dengan gaji sesuai kesepakatan dan kompensasi-kompensasi lainnya. Dalam sistem perekrutan karyawan baru, PT. Trisakti Mustika Graphika harus mempertimbangkan kriteria yang ada di perusahaan agar mendapat nilai yang objektif, akurat sesuai data fakta yang ada dan sesuai dengan kemampuan pelamar. Di dalam penilaian rekrutmen karyawan, kriteria-kriteria yang dibutuhkan di PT.
Trisakti Mustika Graphika yaitu psikotes, interview HRD, pengalaman, pendidikan.

Menurut Kusrini (2007:53) berpendapat bahwa "Maksud dari pencocokan profil (profile matching) adalah sebuah mekanisme pengambilan keputusan dengan mengasumsikan bahwa terdapat tingkat variabel prediktor yang ideal yang harus dimiliki oleh pelamar, bukannya tingkat minimal yang harus dipenuhi atau dilewati”. Dalam profile matching, dilakukan identifikasi terhadap kelompok karyawan yang baik maupun buruk. Para karyawan dalam kelompok tersebut diukur menggunakan beberapa kriteria penilaian. Dari criteria-kriteria tersebut nantinya akan menghasilkan nilai dan akan menghasilkan karyawan yang berkategori baik.

Dari permasalahan yang telah diuraikan di atas, bahwa PT. Trisakti Mustika Graphika membutuhkan sebuah aplikasi yang dapat merekrut karyawan dengan praktis, mudah, dan bisa mendapatkan hasil yang maksimal. Dari penelitian-penelitian yang sebelumnya, telah terdapat permasalahan yang serupa dengan menggunakan metode yang berbeda. Tetapi penulis, memilih metode profile matching dikarenakan metode tersebut cocok dan sesuai dengan permasalahan yang ada di PT. Trisakti Mustika Graphika. Oleh karena itu, penelitian ini mengambil judul Sistem Pendukung Keputusan Rekrutmen Karyawan Dengan 
Menggunakan Metode Profile Matching

\section{Berbasis Web.}

\section{Materials and Methods}

\subsection{Pengertian Sistem}

Menurut Romney (2015: 2) sistem adalah serangkaian dua atau lebih komponen yang saling terkait dan berinteraksi untuk mencapai suatu tujuan.

\subsection{Sistem Pendukung Keputusan}

Sistem Pendukung Keputusan (SPK) atau Decision Support System (DSS) merupakan suatu sistem informasi yang memiliki informasi, pemodelan dan pemanipulasian data. an pemanipulasian data. Sistem ini digunakan untuk membantu pengambil keputusan dalam situasi yang semi terstruktur dan situasi yang tidak terstruktur dimana tidak seorangpun tahu secara pasti bagaimana keputusan seharusnya dibuat (Kusrini, 2007). Karakteristik dari sistem pendukung keputusan (Noviansyah, 2014), yaitu :

1. Mendukung proses pengambilan keputusan suatu organisasi atau perusahaan.

2. Adanya interface manusia/mesin dimana manusia (user) tetap memegang kontrol proses pengambilan keputusan.

3. Mendukung pengambilan keputusan untuk membahas masalah terstruktur, semi terstruktur serta mendukung beberapa keputusan yang saling berinteraksi.
4. Memiliki kapasitas dialog untuk memperoleh informasi sesuai dengan keputusan.

5. Memliki subsistem yang terintegrasi sedemikian rupa sehingga dapat berfungsi sebagai kesatuan sistem.

6. Memiliki dua komponen utama yaitu data dan model

\subsection{Metode Profil Matching}

Metode profile matching adalah sebuah mekanisme pengambilan keputusan dengan mengasumsikan bahwa terdapat tingkat variabel prediktor yang ideal yang harus dipenuhi oleh subyek yang diteliti, bukannya tingkat minimal yang harus dipenuhi atau dilewati.(Kusrini, 2007).

\section{Results and Discussion}

\subsection{Desain Uji Coba}

1. Desain Tampilan Web Untuk Calon Karyawan

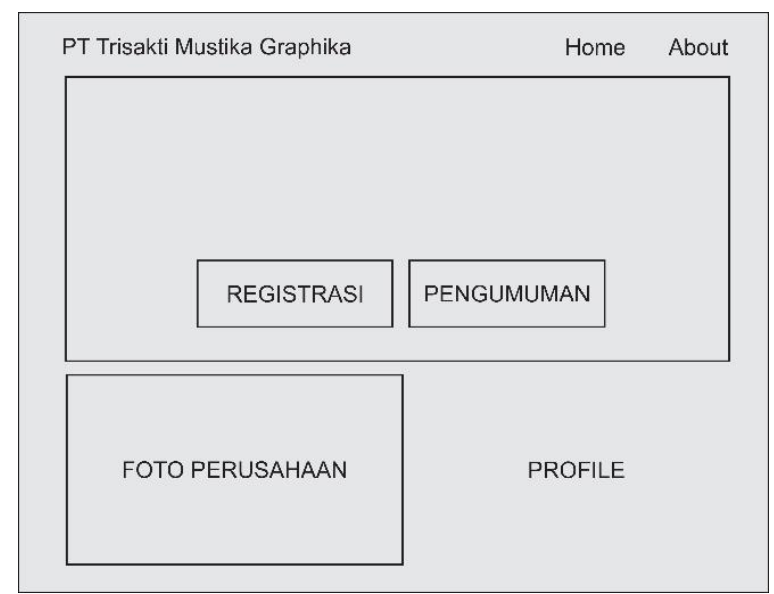

Gambar 1. Desain Tampilan

Web Untuk Calon Karyawan 
Gambar 1. adalah tampilan website yang akan diakses calon karyawan sebelum melakukan proses registrasi. Selain registrasi di website tersebut terdapat pengumuman untuk melihat hasil akhir rekrutmen, dan about untuk melihat profile PT Trisakti Mustika Graphika.

2. Desain Tampilan Registrasi Calon Karyawan

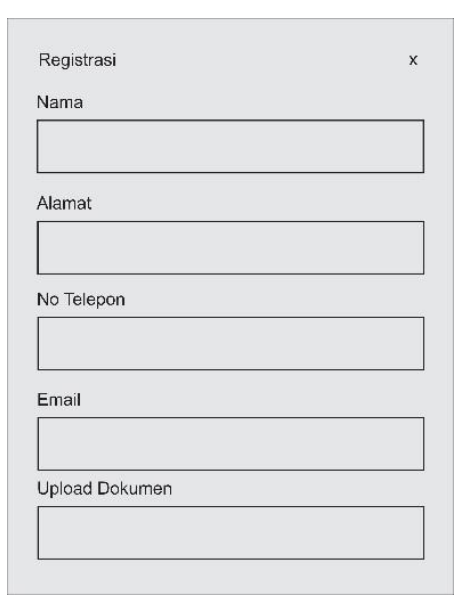

Gambar 2. Desain Tampilan Registrasi Calon Karyawan

Gambar 2. adalah tampilan form registrasi untuk calon karyawan yang akan mendaftar pekerjaan di PT Trisakti Mustika Graphika. Untuk proses pendaftaran calon karyawan diminta untuk melengkapi data dengan cara mengisi form registrasi dengan tepat.
3. Desain Tampilan Pengumuman

Calon Karyawan

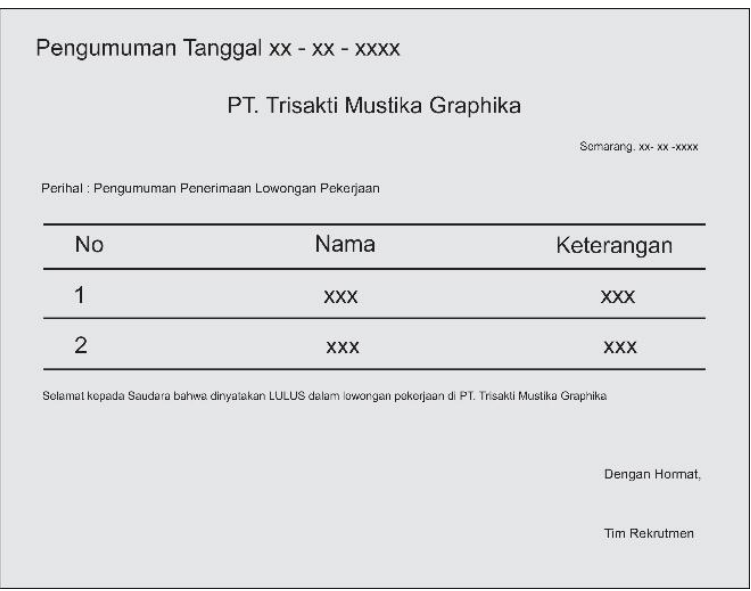

Gambar 3. Desain

Tampilan Pengumuman

Calon Karyawan

Gambar3.19 adalah tampilan halaman pengumuman yang bertujuan agar para calon karyawan agar dapat melihat hasil akhir dari proses rekrutmen di PT Trisakti Mustika Graphika.

4. Desain Tampilan Login Admin / HRD



Gambar 4. Desain

Tampilan Login Admin /

HRD 
Gambar 4. adalah tampilan form login di peruntukan untuk Admin / HRD agar dapat mengelola data. Namun sebelum itu Admin / HRD harus mengisi username dan password dengan tepat, apabila sesuai akan berlanjut ke dashboard admin, apabila tidak sesuai akan tetap di form login Admin / HRD.

5. Desain Tampilan Dashboard Admin



Gambar 5. Desain Tampilan

\section{Dashboard Admin}

Gambar 5. adalah tampilan awal dari website yang diperuntukan untuk Admin / HRD yang berfungsi untuk mengelola data dan melakukan penilaian. Di website tersebut terdapat menu master data yang terdiri dari kriteria, sub kriteria, pembobotan, dan batas minimal kelulusan, kemudian menu calon karyawan yang terdiri dari dokumen persyaratan, daftar calon dan penilaian calon serta menu profile matching, laporan penerimaan.

6. Desain Tampilan Menu Kriteria

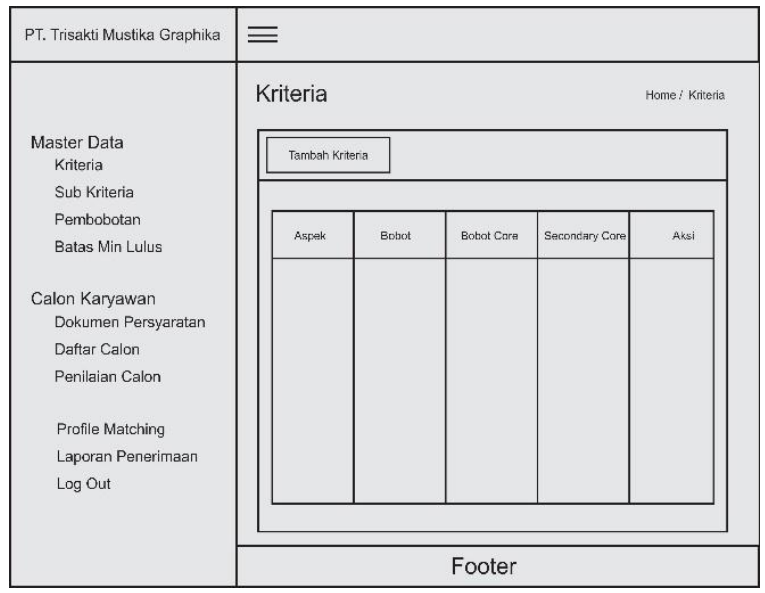

Gambar 6. Desain Tampilan

Menu Kriteria

Gambar 6. adalah tampilan halaman kriteria yang berfungsi untuk mengelola data kriteria seperti mengedit atau menghapus data.

7. Desain Tampilan Form Input Kriteria

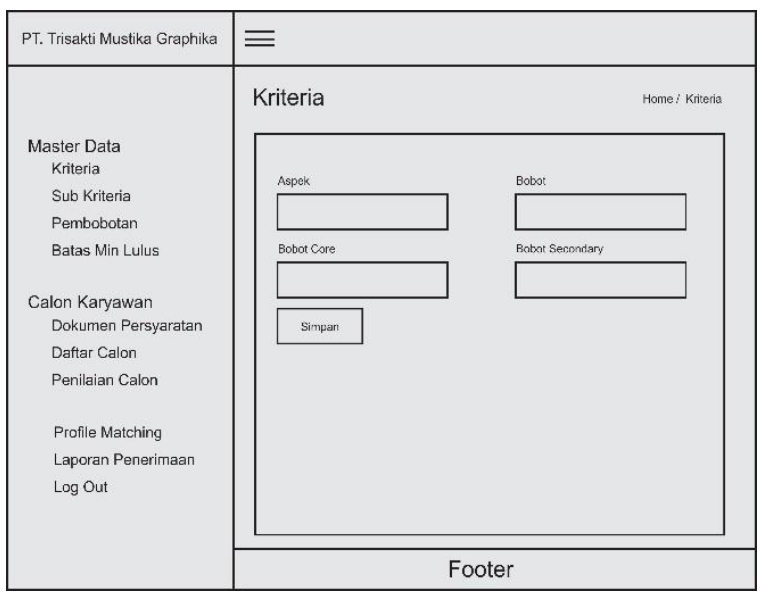

Gambar 7. Desain Tampilan Form Input Kriteria 
Gambar 7. adalah tampilan form input kriteria yang berfungsi untuk menambahkan data kriteria yang diperlukan dalam proses rekrutmen. Untuk melakukan input data Admin / HRD wajib mengisi keseluruhan field seperti aspek, bobot, bobot core dan bobot secondary sebelum menyimpan data.

\section{Desain Tampilan Menu Sub Kriteria}

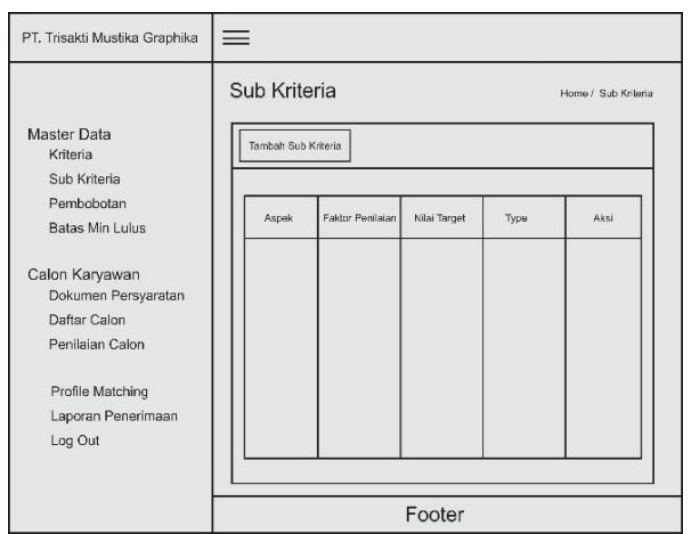

Gambar 8. Desain Tampilan Menu

\section{Sub Kriteria}

Gambar 8. adalah tampilan sub kriteria yang berfungsi untuk mengelola data sub kriteria seperti mengedit atau menghapus data.

9. Desain Tampilan Form Input Sub Kriteria

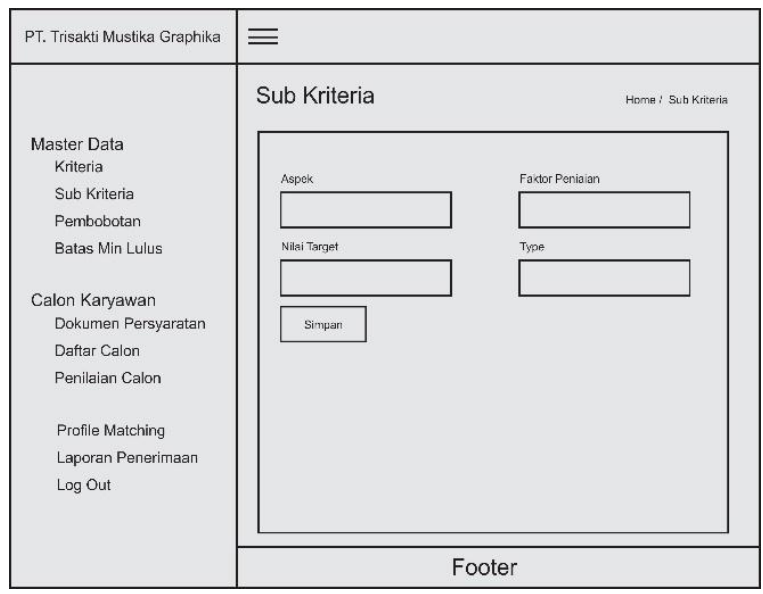

Gambar 9. Desain Tampilan

Form Input Sub Kriteria

Gambar 9. adalah tampilan form input kriteria yang berfungsi untuk menambahkan data sub kriteria yang diperlukan dalam proses rekrutmen. Untuk melakukan input data Admin / HRD wajib mengisi keseluruhan field seperti aspek, faktor penilaian, nilai target dan type sebelum menyimpan data.

\section{Desain Tampilan Menu} Pembobotan

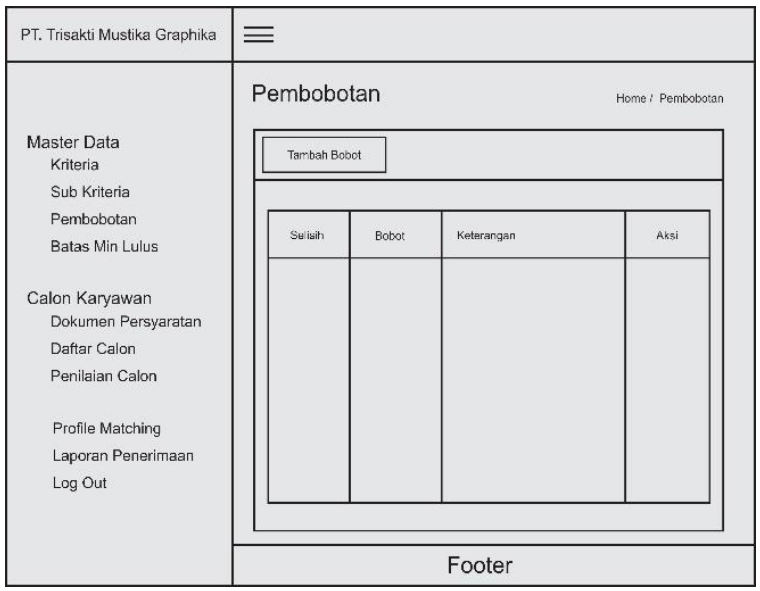

Gambar 10. Desain Tampilan

Menu Pembobotan 
Gambar 10. adalah tampilan halaman pembobotan yang berfungsi untuk mengelola data pembobotan seperti mengedit atau menghapus data.

11. Desain Tampilan Form Input Pembobotan

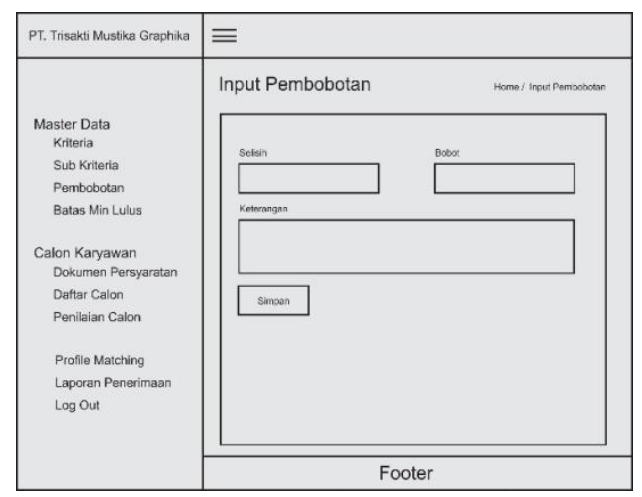

Gambar 11. Desain Tampilan

\section{Form Input Pembobotan}

Gambar 11. adalah tampilan form input pembobotan yang berfungsi untuk menambahkan data pembobotan yang diperlukan dalam proses rekrutmen. Untuk melakukan input data Admin / HRD wajib mengisi keseluruhan field seperti selisih, bobot dan keterangan sebelum menyimpan data.

12. Desain Tampilan Menu Batas Minimal Kelolosan



Gambar 12. Desain Tampilan

Menu Batas Minimal Kelolosan

Gambar 12. adalah tampilan halaman batas minimal lolos yang berfungsi untuk mengelola data batas minimal lolos seperti mengedit atau menghapus data.

13. Desain Tampilan Form Input Batas Minimal Kelolosan



Gambar 13. Desain Tampilan

Form Input Batas Minimal

Kelolosan

GambaR 13. adalah tampilan form input batas minimal lolos yang berfungsi untuk menambahkan data 
batas minimal lolos yang diperlukan dalam proses rekrutmen. Untuk melakukan input data Admin / HRD wajib mengisi field minimal lolos sebelum menyimpan data.

14. Desain Tampilan Menu Dokumen Persyaratan

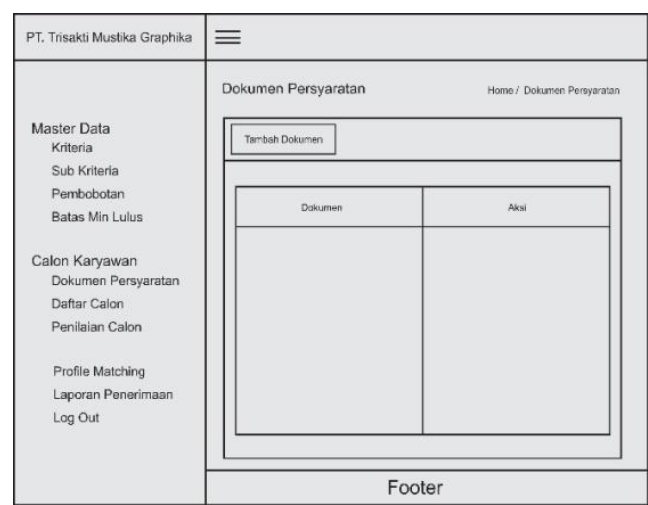

Gambar 14. Desain Tampilan Menu Dokumen Persyaratan

Gambar 14. adalah tampilan halaman dokumen persyaratan yang berfungsi untuk mengelola data dokumen persyaratan seperti mengedit atau menghapus data.

15. Desain Tampilan Form Input Dokumen Persyaratan



Gambar 15. Desain Tampilan

Form Input Dokumen Persyaratan

Gambar 15. adalah tampilan form input dokumen persyaratan yang berfungsi untuk menambahkan data dokumen persyaratan yang diperlukan dalam proses rekrutmen. Untuk melakukan input data Admin / HRD wajib mengisi field dokumen sebelum menyimpan data.

16. Desain Tampilan Menu Daftar Calon



Gambar 16. Desain Tampilan Menu Daftar Calon

Gambar 16. adalah tampilan halaman daftar calon karyawan yang melakukan registrasi di website PT Trisakti Mustika Graphika. 
17. Desain Tampilan Form Input Penilaian

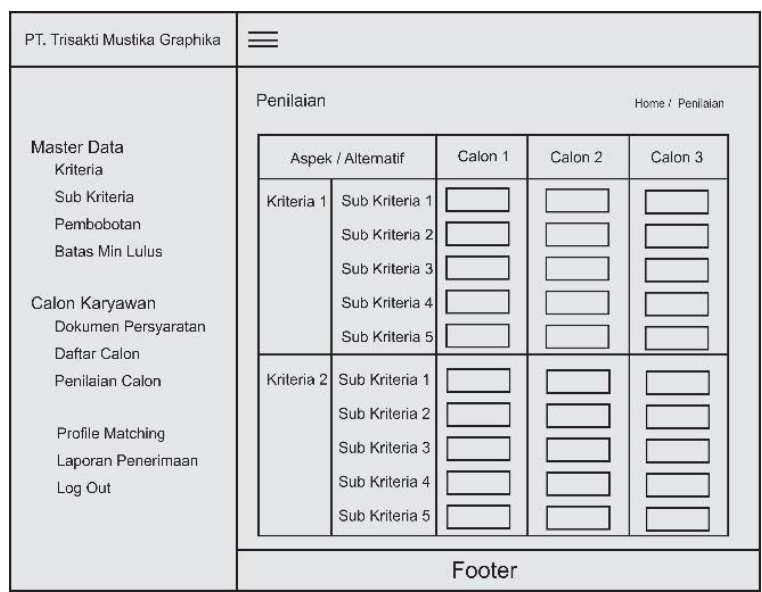

Gambar 17. Desain Tampilan Form

Input Penilaian

Gambar 17. adalah tampilan form input penilaian yang berfungsi untuk melakukan penilaian calon karyawan yang di lakukan oleh Admin / HRD. Untuk melakukan penilaian di tiap sub kriteria Admin / HRD dapat memberikan nilai terendah yaitu 1 dan yang tertinggi yaitu 5.

\section{Desain Tampilan Profile Matching}

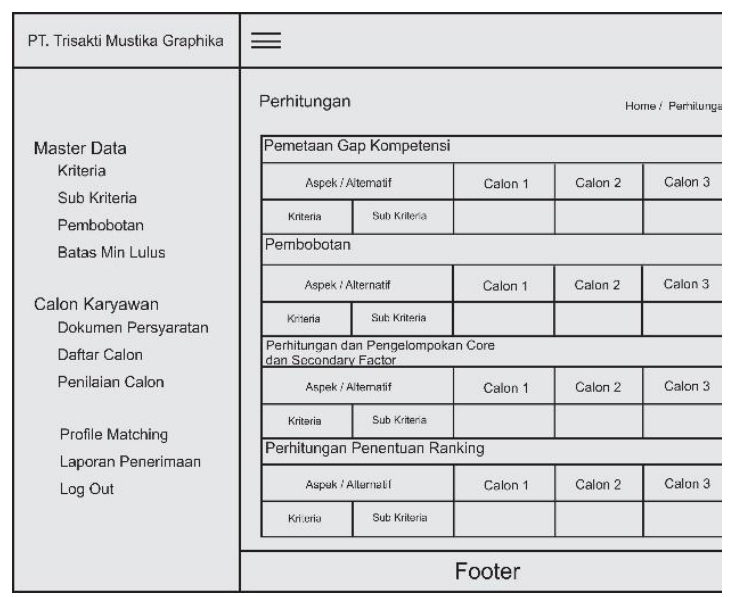

Gambar 18. Desain Tampilan

Profile Matching
Gambar 18. adalah tampilan halaman profile matching yang berfungsi untuk melihat perhitungan sebelum menjadi hasil akhir. Perhitungan profile matching terdapat 4 langkah yaitu pemetaan gap kompetensi, pembobotan, perhitungan dan pengelompokan core dan secondary core, dan yang terakhir perhitungan penentuan rangking.

19. Desain Tampilan Laporan Penerimaan

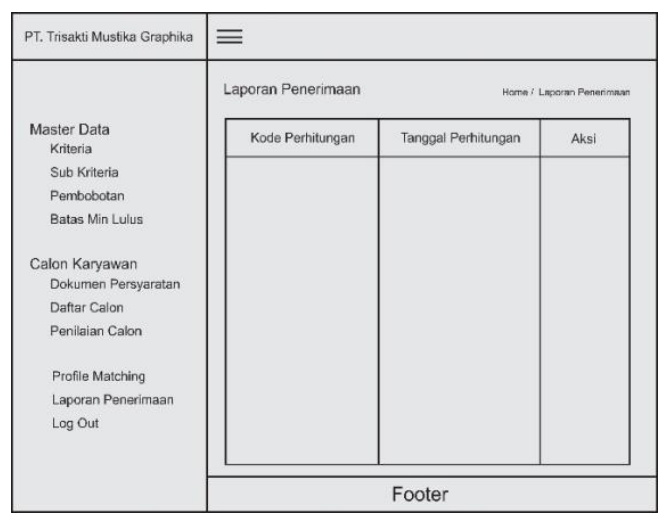

Gambar 19. Desain Tampilan

\section{Laporan Penerimaan}

Gambar 19. adalah tampilan halaman penerimaan yang berfungsi untuk melihat laporan penerimaan calon karyawan yang telah selesai dalam melakukan perhitungan menggunakan metode profile matching. 
20. Desain Tampilan Detail Laporan Penerimaan

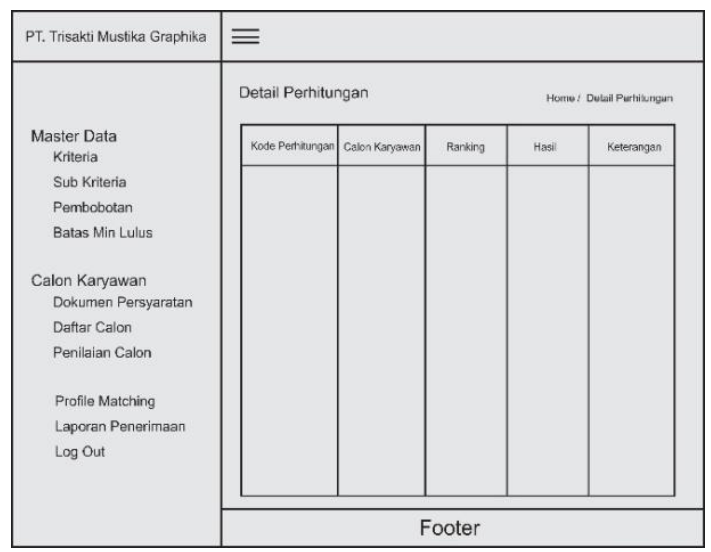

Gambar 20. Desain Tampilan

Detail Laporan Penerimaan

Gambar 20. adalah tampilan detail laporan penerimaan yang berfungsi untuk melihat detail hasil akhir dari perhitungan profile matching.

21. Desain Tampilan Laporan Pengumuman

\begin{tabular}{|c|}
\hline Pengumuman Tanggal 2020-12-21 \\
\hline Pengumuman Tanggal 2020-12-21 \\
\hline Pengumuman Tanggal 2020-11-25 \\
\hline Pengumuman Tanggal 2020-11-25 \\
\hline Pengumuman Tanggal 2020-11-19 \\
\hline Pengumuman Tanggal 2020-11-19 \\
\hline Pengumuman Tanggal 2020-11-17 \\
\hline
\end{tabular}

Gambar 21. Desain Tampilan

Detail Laporan Penerimaan

Gambar 21. adalah tampilan detail laporan pengumuman yang berfungsi untuk melihat hasil pengumuman setelah melalui proses pnilaian sesuai tanggal otomatis.

22. Desain Tampilan Detail Laporan Pengumuman

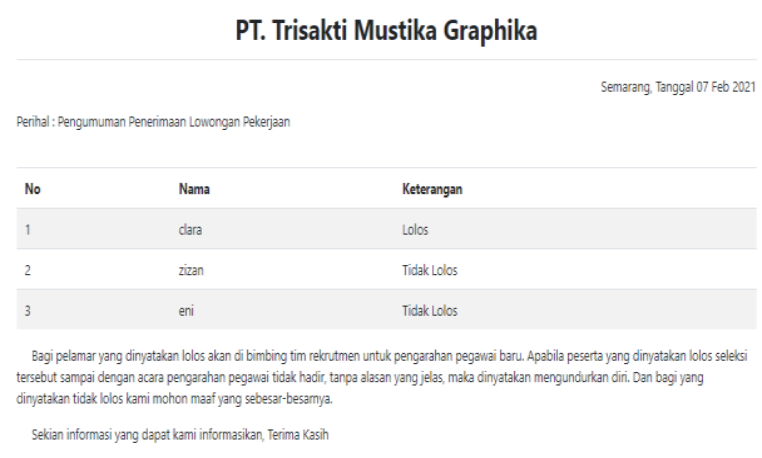

Gambar 22. Desain Tampilan Detail Laporan Penerimaan

Gambar 22. adalah tampilan detail laporan pengumuman yang berfungsi untuk melihat detail hasil pengumuman Lolos atau Tidak Lolos.

\subsection{Conclusions}

1) Dalam merancang sistem yang akan dibuat, penulis menggunakan PHP MyAdmin dan Database MySQL berbasis multiuser ini dapat mempermudah dalam melakukan perhitungan dari hasil penilaian dan pengarsipan data karena semua data terpusat pada satu database sehingga user mendapatkan informasi yang cepat dan tepat. 
2) Keuntungan yang terdapat pada rancangan sistem baru ini bagi calon karyawan adalah memudahkan calon karyawan untuk melakukan registrasi tanpa harus datang ke perusahaan untuk mengirim berkas lamaran pekerjaan

3) Keuntungan yang terdapat pada rancangan sistem baru ini bagi admin / HRD adalah memudahkan admin / HRD dalam melakukan penilaian kepada calon karyawan.

\subsection{References}

[1] Kasmir, Dr. "Manajemen Sumber Daya Manusia (Teori dan Praktik)." Jakarta: Rajawali Pers (2016).
[2] Hasibuan, M. S. (2007). Manajemen Sumber Daya Manusia, cetakan kesembilan. Jakarta: PT Bumi Aksara.

[3] Samsudin, Sadili. 2010. Manajemen Sumber Daya Manusia, Bandung: CV Pustaka Setia.

[4] Kusrini, 2007. Konsep dan Aplikasi Sistem Pendukung Keputusan, Yogyakarta: Andi Ofset.

[5] Noviansyah, Dicky. 2014. Konsep Data Mining vs Sistem Pendukung Keputusan. Yogyakarta : Deepublish.

[6] Romney, Marshall B. dan Steinbart, (2015), Sistem Informasi Akuntansi, Edisi 13, alihbahasa : Kikin Sakinah Nur Safira dan Novita Puspasari, Salemba Empat, Jakarta. 